\title{
Membrane-less and Non-Evaporative Desalination of Hypersaline Brines by Temperature Swing Solvent Extraction
}

\author{
Chanhee Boo, ${ }^{\dagger}$ Robert K. Winton, ${ }^{\dagger}$ Kelly M. Conway, ${ }^{\dagger}$ and Ngai Yin Yip*, ${ }^{\dagger},+\infty$ \\ ${ }^{\dagger}$ Department of Earth and Environmental Engineering, Columbia University, New York, New York 10027-6623, United States \\ ${ }^{\ddagger}$ Columbia Water Center, Columbia University, New York, New York 10027-6623, United States
}

Supporting Information

ABSTRACT: Hypersaline brines are of growing environmental importance but are technologically under-served by today's desalination methods. Temperature swing solvent extraction (TSSE) is a radically different desalination technology that is membrane-less and not based on evaporative phase change. TSSE utilizes lowtemperature heat and a low-polarity solvent with temperature-dependent water solubility for the selective extraction of water over salt from saline feeds. This study demonstrates TSSE desalination of high-salinity brines simulated by $\mathrm{NaCl}$ solutions with three amine solvents: diisopropylamine (DIPA), N-ethylcyclohexylamine (ECHA), and N,N-dimethylcyclohexylamine (DMCHA). We show that TSSE can desalinate brines with salinities as high as $\approx 234000 \mathrm{ppm}$ total dissolved solids (i.e., 4.0 $\mathrm{M} \mathrm{NaCl}$ ) and achieve salt removals up to $98.4 \%$. Among the solvents, DIPA exhibited the highest water extraction efficiency whereas ECHA and DMCHA produced water

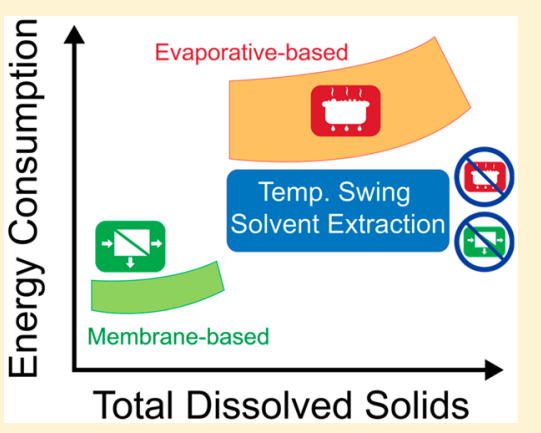
with the lowest salt content and solvent residue content, respectively. Lastly, a high water recovery of $>50 \%$ was demonstrated for TSSE desalination of $1.5 \mathrm{M} \mathrm{NaCl}$ brine using DIPA in semibatch experiments with multiple extraction cycles. This study underscores the unique capabilities of TSSE for the desalination of hypersaline brines.

\section{INTRODUCTION}

Hypersaline brines are of growing environmental concern. ${ }^{1,2}$ Prominent examples of such high-salinity brines include water produced by the oil and gas industry, ${ }^{3,4}$ waste streams of minimum/zero-liquid discharge operations, ${ }^{5}$ inland desalination concentrate, ${ }^{6,7}$ landfill leachate, ${ }^{8}$ and flue gas desulfurization wastewater. ${ }^{9}$ Very high total dissolved solids (TDS) of $>60000 \mathrm{ppm}$ pose considerable technical challenges during treatment. ${ }^{10}$ Reverse osmosis (RO) is the most energy-efficient and cost-effective technique for desalinating seawater. ${ }^{11}$ However, because osmotic pressure scales with TDS concentration, exceedingly high operating pressures needed to overcome the osmotic pressure of hypersaline brines preclude the application of RO. ${ }^{12,13}$ Evaporation-based thermal methods, e.g., multiple-effect distillation, thermal brine concentrator, and crystallizer, are the prevailing processes for desalinating or dewatering highly concentrated brines. ${ }^{5,14,15}$ These processes achieve separation by phase change(s) between liquid and vapor water. ${ }^{16,17}$ However, because the enthalpy of vaporization for water is huge $\left(\approx 630 \mathrm{kWh} / \mathrm{m}^{3}\right)$ and the energy efficiency of evaporative phase change methods is thermodynamically constrained, ${ }^{18,19}$ these processes inherently require intensive thermal energy input, ${ }^{20}$ even though the quality of energy is lower (heat as opposed to electricity for RO). ${ }^{21}$ Therefore, there is a pressing need to develop energyefficient technologies for the more sustainable desalination of environmentally relevant hypersaline streams.

Solvent extraction is a separation method widely employed for chemical engineering processes. ${ }^{2,23}$ The relatively inexpensive, simple, and effective separation technique is used in a wide range of industries, including production of fine organic compounds, ${ }^{24,25}$ purification of natural products, ${ }^{26}$ and extraction of valuable metal complexes. ${ }^{27}$ Solvent extraction can be an alternative desalination approach that is radically different from conventional methods because it is membraneless and not based on evaporative phase change. Application of solvent extraction for desalination was first explored using amine solvents in the $1950 \mathrm{~s}^{28}$ but the effort was limited to desalting brackish water of relatively low salinity $(<10000 \mathrm{ppm}$ TDS $).{ }^{29}$ More recently, the technique was investigated for desalination of seawater simulated by a $3.5 \%(w / w) \mathrm{NaCl}$ solution with decanoic acid as the solvent. ${ }^{30}$

In this study, we demonstrate temperature swing solvent extraction (TSSE) desalination of high-salinity brines using three amine solvents. The performance metrics of water extraction, salt removal, product water quality, and osmotic pressure reduction were evaluated, and the most suitable solvents for specific performance objectives were identified. Attainable water recovery for desalination of high-salinity brines was further assessed in semibatch TSSE experiments with multiple extraction cycles. The implications of TSSE as an alternative membrane-less and non-evaporative technique for hypersaline desalination are discussed.

Received: March 21, 2019

Revised: April 19, 2019

Accepted: April 30, 2019

Published: April 30, 2019 


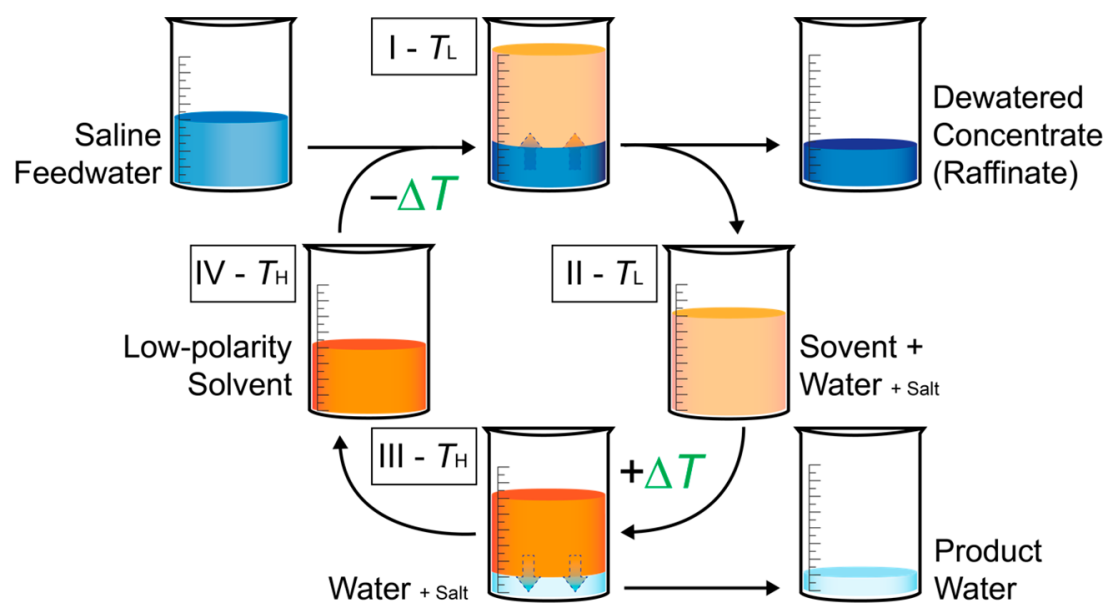

Figure 1. Schematic illustrating the working principles of temperature swing solvent extraction. A low-polarity solvent that is immiscible with aqueous solutions and exhibits temperature-dependent water solubility is used to extract water from the saline feed. A moderate temperature swing of $\approx 20-60{ }^{\circ} \mathrm{C}$ depresses the solubility of water in the solvent, thus driving separation to yield product water and a dewatered concentrate (raffinate).
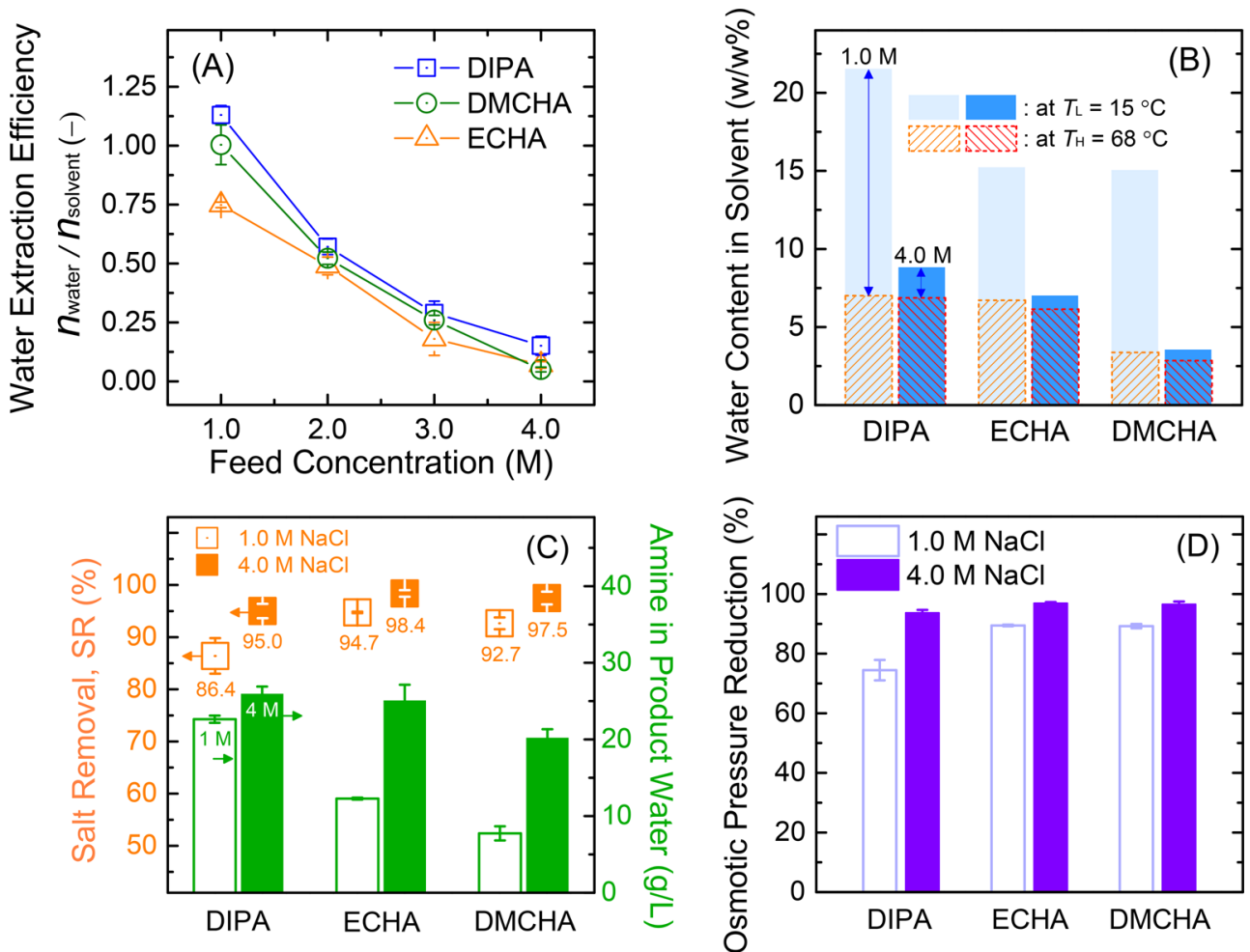

Figure 2. (A) Water extraction efficiency of DIPA, DMCHA, and ECHA as a function of brine $(\mathrm{NaCl})$ concentration, expressed as the mole ratio of product water to solvent. (B) Water content in solvents during TSSE desalination. The difference in water content in amine at low and high temperatures (solid and diagonal patterned columns, respectively) corresponds to the amount of product water. (C) Salt removal and residual solvent concentrations in the product water (symbols, left vertical axis and columns, right vertical axis, respectively) for desalination of 1.0 and 4.0 $\mathrm{M} \mathrm{NaCl}$ brines. (D) Osmotic-pressure reduction of product water relative to saline feed for 1.0 and $4.0 \mathrm{M} \mathrm{NaCl}$ by TSSE desalination with DIPA, ECHA, and DMCHA. For all plots, data and error bars are means and standard deviations, respectively, from triplicate experiments.

\section{TEMPERATURE SWING SOLVENT EXTRACTION}

Working Principles of TSSE Desalination. TSSE employs a low-polarity solvent with temperature-dependent water solubility, ${ }^{28}$ and the working principles are depicted in Figure 1. First, saline feedwater is combined with the solvent (step I), with both at temperature $T_{\mathrm{L}}$. Due to the low polarity of the solvent, the two liquids are immiscible and a biphasic mixture is formed. However, some water from the aqueous phase partitions into the solvent phase because of hydrophilic moieties on the solvent chemical structure. That is, the solvent extracts water from the saline feedwater, leaving a concentrated raffinate, whereas ionic salt species do not favor partitioning into the low-polarity solvent. The dewatered concentrate is physically separated (step II), and the water-in-solvent extract is brought to temperature $T_{\mathrm{H}}$, with a moderate $\Delta T$ of $\approx 20-60$ ${ }^{\circ} \mathrm{C}$. Because the solubility of water in the solvent decreases with an increase in temperature, the temperature swing from $T_{\mathrm{L}}$ to $T_{\mathrm{H}}$ causes water to demix from the solvent to form a 
biphasic aqueous-solvent mixture (step III). The product water, containing trace amount of salt, is easily decanted from the solvent as the two liquids are immiscible, and the regenerated solvent is cycled back for reuse after returning to temperature $T_{\mathrm{L}}$ (step IV).

To dissolve water while being immiscible with the aqueous phase, the solvent should possess hydrophilic moieties in a mainly hydrophobic chemical structure. Amines, for instance, have a nitrogen atom with a lone pair of electrons that can form a hydrogen bond with water molecules. ${ }^{31}$ Alkyl groups adjacent to the nitrogen atom further increase the dipole moment of the amine molecule by the inductive effect, thus increasing the affinity for water molecules. ${ }^{28}$ The solubility of water in the solvent should also be highly sensitive to temperature in the operating range. At higher temperatures, the free rotation of the alkyl groups on amines increases. ${ }^{32}$ Hence, the effect of steric hindrance is amplified, and fewer water molecules are associated with the $\mathrm{N}$ atom, resulting in a decrease in the water solubility of the amine solvent. ${ }^{28}$ This study employed one tertiary amine and two secondary amines for the desalination of hypersaline brines, but other appropriate solvents can also be used for TSSE.

\section{MATERIALS AND METHODS}

A detailed description of the materials and methods can be found in the Supporting Information and is briefly presented here.

Temperature Swing Solvent Extraction Desalination Experiments. Diisopropylamine (DIPA), N-ethylcyclohexylamine (ECHA), and N,N-dimethylcyclohexylamine (DMCHA) were evaluated for TSSE desalination of hypersaline brines simulated with $1.0-4.0 \mathrm{M}$ aqueous $\mathrm{NaCl}$ solutions. The chemical structure and properties of the solvents are summarized in Table S1. First, $40 \mathrm{~g}$ of amine solvent and 40 $\mathrm{mL}$ of $\mathrm{NaCl}$ brine were combined in a glass medium bottle and gently mixed. After equilibration of the biphasic mixture at a $T_{\mathrm{L}}$ of $15^{\circ} \mathrm{C}$ for $1 \mathrm{~h}$, the water-in-solvent extract (i.e., light phase of the biphasic mixture in step I of Figure 1) was carefully transferred to another medium bottle using a glass pipet. The extract was placed in a high-temperature bath at a $T_{\mathrm{H}}$ of $68{ }^{\circ} \mathrm{C}$ for $1 \mathrm{~h}$ to drive phase separation, yielding the aqueous product water (heavy phase in step III of Figure 1). The product water was carefully separated using a glass pipet and weighed to determine the water extraction efficiency, defined as the mole ratio of product water to solvent used. Pictures of the TSSE experiment are shown in Figure S1. The compositions of the product water, final solvent, and concentrated raffinate were further analyzed (details in the Supporting Information). For semibatch TSSE experiments to evaluate total water recovery, $40 \mathrm{~g}$ of solvent was continually reused in multiple cycles for stepwise water extraction from a $1.5 \mathrm{M} \mathrm{NaCl}$ brine sample with an initial volume of $40 \mathrm{~mL}$, such that the raffinate was progressively concentrated over the extraction cycles.

\section{RESULTS AND DISCUSSION}

TSSE Can Desalinate Ultra-High-Salinity Brines. TSSE desalination of hypersaline brines was evaluated using a $\mathrm{NaCl}$ solution with concentrations ranging from 1.0 to $4.0 \mathrm{M}$, which correspond to TDS of $\approx 58500-234000 \mathrm{ppm}$. Water extraction efficiencies of DIPA, ECHA, and DMCHA are presented in Figure 2A. DIPA exhibited the highest water extraction efficiency over the entire salinity range investigated, followed by DMCHA and ECHA. For every mole of DIPA, DMCHA, and ECHA, approximately 1.13, 1.00, and $0.75 \mathrm{~mol}$ of water were extracted, respectively, from $1.0 \mathrm{M} \mathrm{NaCl}$ brine. The water extraction efficiency monotonically decreased with an increase in $\mathrm{NaCl}$ concentration because the partitioning of water molecules into the solvent (step I of Figure 1) is reduced for brines with higher chemical potentials, i.e., higher salinities (or, equivalently, more saline feeds have lower water potentials). ${ }^{33,34}$ Critically, the three amine solvents investigated produced water even from $4.0 \mathrm{M} \mathrm{NaCl}$ with a TDS concentration $>6$ times that of seawater, demonstrating the promise of TSSE for ultra-high-salinity desalination. Product water volumes extracted per solvent weight across the salinity range for the three amines are provided in Figure S2.

The water extraction efficiency is determined by the sensitivity of water solubility to temperature change, a key thermophysical property of solvents for TSSE desalination. The water content in all three solvents decreased with an increase in temperature from $15{ }^{\circ} \mathrm{C}\left(T_{\mathrm{L}}\right)$ to $68^{\circ} \mathrm{C}\left(T_{\mathrm{H}}\right)$ during TSSE desalination of both 1.0 and $4.0 \mathrm{M}$ brines (Figure $2 \mathrm{~B}$ ). Hence, product water demixes from the oversaturated solvent until the water content reaches the lowered solubility limit (step III of Figure 1). DIPA exhibited a more significant change in water solubility from the temperature swing (indicated by the blue arrow) than the other two amine solvents, which explains the highest water extraction efficiency performance (Figure 2A). For $1.0 \mathrm{M} \mathrm{NaCl}$, water contents in ECHA and DMCHA were comparable at $T_{\mathrm{L}}$ (light blue column in Figure 2B) but DMCHA retained a much smaller amount of water than ECHA at $T_{\mathrm{H}}$ (orange diagonal patterned column). The greater change in water solubility with $\Delta T$ yielded a higher water extraction efficiency for DMCHA than for ECHA during TSSE desalination of $1.0 \mathrm{M} \mathrm{NaCl}$ (Figure 2A). For different saline feed concentrations, the water content of each solvent at $T_{\mathrm{H}}$ was comparable (orange and red diagonal patterned columns), suggesting that the oversaturated solvent released water until it reached the same water solubility (or water content) at $T_{\mathrm{H}}$, although the solvent has extracted different amounts of water from the 1.0 and $4.0 \mathrm{M}$ brines at $T_{\mathrm{L}}$.

Greater Salt Removal Is Achieved for Higher Salinities. The product water quality of TSSE desalination was evaluated for salt $(\mathrm{NaCl})$ removal and residual solvent concentration (Figure 2C). Salt removal, SR, is defined as the percentage of $\mathrm{NaCl}$ removed from the product water relative to the saline feedwater (i.e., $\mathrm{SR}=1-C_{\mathrm{p}} / C_{\mathrm{f}}$, where $C$ is concentration and subscripts $\mathrm{p}$ and $\mathrm{f}$ denote the product and feed, respectively). High salt removals of $>90 \%$ were achieved with all solvents for 1.0 and 4.0 M brines (orange symbols and left vertical axis), with the exception of DIPA exhibiting an SR of $86.4 \%$ for $1.0 \mathrm{M} \mathrm{NaCl}$. In particular, ECHA showed the highest salt removals of $94.7 \%$ and $98.4 \%$ among the solvents assessed for TSSE desalination of 1.0 and $4.0 \mathrm{M} \mathrm{NaCl}$ brines, respectively. Salt removal was higher for $4.0 \mathrm{M} \mathrm{NaCl}$ brine than for $1.0 \mathrm{M} \mathrm{NaCl}$ brine with all amines. The enhanced salt removal at higher $\mathrm{NaCl}$ concentrations highlights that TSSE is especially favorable for ultrahigh salinities. Product water salt concentrations are shown in Figure S3. No salts were detected to have accumulated in the final solvent, i.e., after lowtemperature demixing (step IV of Figure 1), signifying the recyclability of the amine solvents.

Residual solvent concentrations in the product water for TSSE desalination of 1.0 and $4.0 \mathrm{M} \mathrm{NaCl}$ brines are presented in Figure 2C (green columns and right vertical axis). For all 

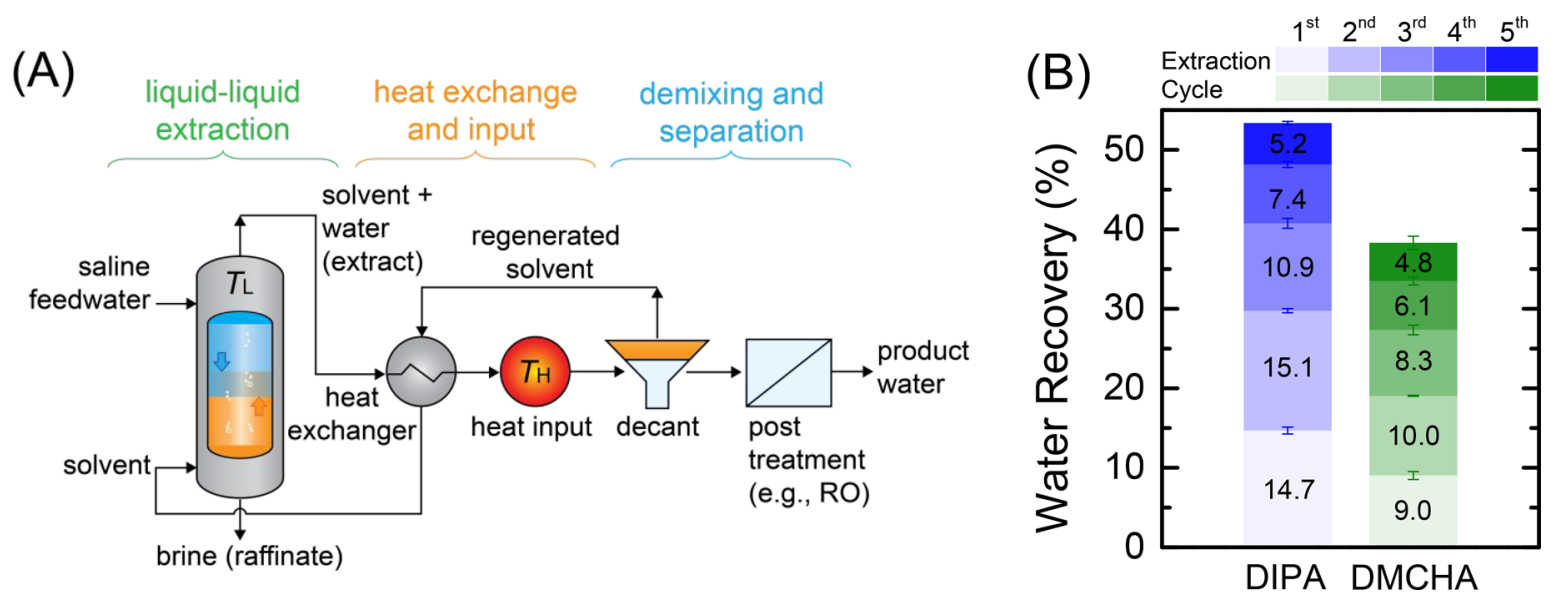

Figure 3. (A) Process flow diagram of a continuous TSSE desalination process. (B) Water recovery achieved by TSSE desalination of $1.5 \mathrm{M} \mathrm{NaCl}$ brine with DIPA and DMCHA in semibatch experiments with multiple (five) extraction cycles. The solvent is reused for the next cycle without being replenished, and the concentrated raffinate at the end of a cycle is the feed for the next extraction. Water recovery of each extraction cycle is denoted in the column segments.

amines, residual solvent concentrations in the product water desalinated from $1.0 \mathrm{M} \mathrm{NaCl}$ are lower compared to those for 4.0 $\mathrm{M} \mathrm{NaCl}$ (empty and solid columns, respectively). Among the solvents evaluated, DMCHA yielded product water with the lowest amine residue content for both 1.0 and $4.0 \mathrm{M} \mathrm{NaCl}$ brines. Although the amine residues would render the product water unsuitable for potable use, the output stream may be employed for other fit-for-purpose applications, such as internal reuse of TSSE-treated hydraulic fracturing water from shale gas production. Alternatively, the trace solvent content can be effectively removed by an optional posttreatment, such as reverse osmosis, to yield higher product water quality (results and discussion below). Solvent concentrations in the dewatered raffinate are much lower than in the product water $(9.0,2.5$, and $2.0 \mathrm{~g} / \mathrm{L}$ for DIPA, ECHA, and DMCHA, respectively) for $4.0 \mathrm{M} \mathrm{NaCl}$ desalination (Figure S4). This is because partitioning of the solvent into aqueous phases with a significantly higher salinity is thermodynamically less favorable. The residual solvent can further be removed from the raffinate and recovered for reuse by warming the raffinate to $T_{\mathrm{H}}$, inducing the solvent to demix from the aqueous solution. After this phase separation at 68 ${ }^{\circ} \mathrm{C}$, residual solvent in the raffinates are substantially decreased to $0.57,0.45$, and $0.07 \mathrm{~g} / \mathrm{L}$ for DIPA, ECHA, and DMCHA, respectively (Figure S4). The consistently low solvent concentrations in product water and dewatered raffinate across the salinity range underlines the suitability of DMCHA for TSSE where minimal solvent loss is a specific performance objective.

The Osmotic Pressure of Hypersaline Brine Is Significantly Reduced. The salt concentration in the product water is drastically reduced compared to that in the hypersaline feed, but the residual solvent is an additional impurity (Figure 2C). A more inclusive parameter that accounts for both salt and solvent contributions is the product water osmotic pressure $(\pi)$. The osmotic pressure reduction of the product water relative to the hypersaline feed, $1-\pi_{\mathrm{p}} / \pi_{\mathrm{f}}$, is shown in Figure 2D for TSSE desalination of 1.0 and $4.0 \mathrm{M}$ $\mathrm{NaCl}$ brines (details about osmotic pressure analysis are given in the Supporting Information).

DIPA, ECHA, and DMCHA achieved 74.5\%, 89.5\%, and $89.2 \%$ osmotic pressure reductions, respectively, for $1.0 \mathrm{M}$
$\mathrm{NaCl}$ brine, whereas larger osmotic pressure reductions of $93.7 \%, 96.9 \%$, and $96.6 \%$, respectively, are observed for the product water from $4.0 \mathrm{M} \mathrm{NaCl}$ desalination. The trends of osmotic pressure reduction are similar to those of salt removal for the three amine solvents and different salinities, albeit slightly lower (comparing Figure $2 \mathrm{D}$ and the orange square symbols of Figure 2C), the difference being the effect of undesired solvent residues in product water. Thus, the amine residues only marginally influenced the TSSE desalination performance metric of osmotic pressure reduction. The osmotic pressure of the initial $4.0 \mathrm{M} \mathrm{NaCl}$ feed is 261 bar, considerably beyond the operating range of conventional $\mathrm{RO}$; product water osmotic pressures after TSSE desalination were substantially decreased to $\approx 16.3,8.0$, and 8.9 bar with DIPA, ECHA, and DMCHA, respectively, below the seawater osmotic pressure of $\approx 25$ bar. With the reduced osmotic pressures, the product water can be further polished using RO or other post-treatment with a significantly lower energy demand.

High Water Recovery of Hypersaline Brines by TSSE. TSSE desalination can be readily scaled up. Figure 3A depicts a process flow diagram of a conceptual TSSE desalination facility operated as a continuous process. Saline feedwater is the heavy phase and enters the liquid-liquid extraction column toward the top. Solvent, the light phase, is introduced near the bottom of the column to obtain a countercurrent flow. The solvent extracts water from the saline stream at temperature $T_{\mathrm{L}}$, and the denser aqueous concentrate exits the column at the bottom as the raffinate. The less dense water-in-solvent extract leaves the column from the top and is channeled to the heat exchanger. Heat transfers across the exchanger, between the hot regenerated solvent on the other side and the extract stream. The water-in-solvent extract is further heated to $T_{\mathrm{H}}$ by a thermal energy input. The warmed extract is then directed to the decanting separator, where gravity-aided demixing separates the extract into a biphasic mixture to yield product water and regenerated solvent. After exchanging heat with the incoming extract, the recovered solvent is cycled back to the extraction column for reuse. The product water can be further polished in a post-treatment step to meet specific water quality requirements. 
Continuous operation of TSSE desalination was simulated by semibatch experiments with multiple extraction cycles, using DIPA or DMCHA as the solvent and $1.5 \mathrm{M} \mathrm{NaCl}$ as the feed brine. The dewatered raffinate and regenerated solvents were reused for subsequent extraction cycles to evaluate the total water recovery of continuous TSSE desalination, defined as the portion of the initial feed volume desalinated to product water. Overall, water recovery decreased with each sequential extraction cycle for both DIPA and DMCHA as the raffinate is progressively concentrated (Figure $3 \mathrm{~B}$ ). The slightly higher water recovery of the second extraction cycle compared to the first is an artifact of the experimental procedure [initial solvents of the pure amine have very low water contents (Table S1)]. After five TSSE cycles, DIPA and DMCHA achieved 53.4\% and $38.3 \%$ water recoveries, respectively, in desalination of 1.5 $\mathrm{M} \mathrm{NaCl}$ brine. A basic analysis estimates the energy consumption of continuous TSSE desalination of $1.5 \mathrm{M}$ $\mathrm{NaCl}$ with DIPA at $50 \%$ water recovery to be between 39 and $77 \mathrm{kWh} / \mathrm{m}^{3}$ of product water, with heat exchanger efficiencies of $90 \%$ and $80 \%$, respectively (calculation details in the Supporting Information). The semibatch experiments demonstrate that high water recoveries are achievable in TSSE desalination of hypersaline brines and further validate the recyclability of solvents for multiple extraction cycles.

The effectiveness of $\mathrm{RO}$ post-treatment (as depicted in Figure $3 \mathrm{~A}$ ) in removing the residual solvents from the product water was evaluated (Figure S5). DIPA and DMCHA with relatively high molecular weights (101.2 and 127.2, respectively) were effectively removed by the $\mathrm{RO}$ membrane, with rejections of $>98 \%$ and $>96 \%$, respectively. The RO posttreatment utilized a relatively low hydraulic pressure of 13.8 bar as the osmotic pressure of the product water from TSSE desalination is minimal, representing a low energy cost for the post-treatment separation. Furthermore, higher rejections will be achieved for crossflow RO modules in actual operation, compared to the dead-end filtration employed in this study.

\section{IMPLICATIONS FOR HYPERSALINE DESALINATION}

This study demonstrates that temperature swing solvent extraction is uniquely suited for the desalination of hypersaline brines, a segment of intensifying environmental importance but not accessible by RO and handicapped by intrinsically poor energy efficiencies of evaporative methods. The technology is not restricted by feed solution properties, unlike membranebased RO with hydraulic/osmotic pressure limitation. Because TSSE does not require a phase change of water, the penalizing energy cost associated with the enthalpy of vaporization is inventively sidestepped and significantly higher energy efficiencies are attainable. As only moderate temperatures are needed $\left(<70{ }^{\circ} \mathrm{C}\right.$ in this study), the heat input can be supplied by low-grade thermal sources such as industrial waste heat, shallow-well geothermal heat, and low-concentration solar collectors, further enhancing the sustainability of TSSE. The solvent is at the core of TSSE. This study shows that specific performance objectives can be achieved by rational solvent selection, specifically, DIPA for high water extraction efficiency, ECHA for high salt removal, and DMCHA for low solvent loss. Other solvents with different chemical structures and properties can yield better performances to further expand the prospects of TSSE for energy-efficient and cost-effective desalination of high-salinity brines.

\section{ASSOCIATED CONTENT}

\section{Supporting Information}

The Supporting Information is available free of charge on the ACS Publications website at DOI: 10.1021/acs.estlett.9b00182.

Details about materials and chemicals, including characterization of salt concentrations and solvent residues, analysis of water content in solvent, determination of osmotic pressure, solvent removal with deadend RO, and assessment of energy consumption; chemical structure and properties of amine solvents (Table S1); pictures of the TSSE experiment steps (Figure S1); product water volume extracted per solvent weight (Figure S2); residual salt concentration in product water (Figure S3); residual amine concentration in concentrated raffinate (Figure S4); and rejection of DIPA and DMCHA by the RO membrane in a dead-end setup (Figure S5) (PDF)

\section{AUTHOR INFORMATION}

\section{Corresponding Author}

*E-mail: n.y.yip@columbia.edu. Telephone: +1 (212) 8542984.

ORCID

Chanhee Boo: 0000-0003-4595-9963

Ngai Yin Yip: 0000-0002-1986-4189

Notes

The authors declare no competing financial interest.

\section{REFERENCES}

(1) Ahmad, N.; Baddour, R. E. A review of sources, effects, disposal methods, and regulations of brine into marine environments. Ocean Coast Manage 2014, 87, 1-7.

(2) Pramanik, B. K.; Shu, L.; Jegatheesan, V. A review of the management and treatment of brine solutions. Environ. Sci-Wat Res. 2017, 3 (4), 625-658.

(3) Benko, K. L.; Drewes, J. E. Produced water in the Western United States: Geographical distribution, occurrence, and composition. Environ. Eng. Sci. 2008, 25 (2), 239-246.

(4) Gregory, K. B.; Vidic, R. D.; Dzombak, D. A. Water Management Challenges Associated with the Production of Shale Gas by Hydraulic Fracturing. Elements 2011, 7 (3), 181-186.

(5) Tong, T. Z.; Elimelech, M. The Global Rise of Zero Liquid Discharge for Wastewater Management: Drivers, Technologies, and Future Directions. Environ. Sci. Technol. 2016, 50 (13), 6846-6855.

(6) Brady, P. V.; Kottenstette, R. J.; Mayer, T. M.; Hightower, M. M. Inland Desalination: Challenges and Research Needs. Journal of Contemporary Water Research \& Education 2005, 132 (1), 46-51.

(7) Stanford, B. D.; Leising, J. F.; Bond, R. G.; Snyder, S. A. Chapter 11 Inland Desalination: Current Practices, Environmental Implications, and Case Studies in Las Vegas, NV. In Sustainability Science and Engineering; Escobar, I. C., Schäfer, A. I., Eds.; Elsevier, 2010; Vol. 2, pp 327-350.

(8) Renou, S.; Givaudan, J. G.; Poulain, S.; Dirassouyan, F.; Moulin, P. Landfill leachate treatment: Review and opportunity. J. Hazard. Mater. 2008, 150 (3), 468-493.

(9) Karanikola, V.; Boo, C.; Rolf, J.; Elimelech, M. Engineered Slippery Surface to Mitigate Gypsum Scaling in Membrane Distillation for Treatment of Hypersaline Industrial Wastewaters. Environ. Sci. Technol. 2018, 52, 14362.

(10) Davenport, D. M.; Deshmukh, A.; Werber, J. R.; Elimelech, M. High-Pressure Reverse Osmosis for Energy-Efficient Hypersaline Brine Desalination: Current Status, Design Considerations, and Research Needs. Environ. Sci. Technol. Lett. 2018, 5 (8), 467-475. 
(11) Elimelech, M.; Phillip, W. A. The Future of Seawater Desalination: Energy, Technology, and the Environment. Science 2011, 333 (6043), 712-717.

(12) Chen, X.; Yip, N. Y. Unlocking High-Salinity Desalination with Cascading Osmotically Mediated Reverse Osmosis: Energy and Operating Pressure Analysis. Environ. Sci. Technol. 2018, 52 (4), 2242-2250.

(13) Henthorne, L.; Boysen, B. State-of-the-art of reverse osmosis desalination pretreatment. Desalination 2015, 356, 129-139.

(14) Shaffer, D. L.; Arias Chavez, L. H.; Ben-Sasson, M.; RomeroVargas Castrillon, S.; Yip, N. Y.; Elimelech, M. Desalination and Reuse of High-Salinity Shale Gas Produced Water: Drivers, Technologies, and Future Directions. Environ. Sci. Technol. 2013, 47 (17), 9569-9583.

(15) Fakhru'l-Razi, A.; Pendashteh, A.; Abdullah, L. C.; Biak, D. R. A.; Madaeni, S. S.; Abidin, Z. Z. Review of technologies for oil and gas produced water treatment. J. Hazard. Mater. 2009, 170 (2-3), 530551.

(16) Mistry, K. H.; McGovern, R. K.; Thiel, G. P.; Summers, E. K.; Zubair, S. M.; Lienhard, J. H. Entropy Generation Analysis of Desalination Technologies. Entropy 2011, 13 (10), 1829-1864.

(17) Deshmukh, A.; Boo, C.; Karanikola, V.; Lin, S. H.; Straub, A. P.; Tong, T. Z.; Warsinger, D. M.; Elimelech, M. Membrane distillation at the water-energy nexus: limits, opportunities, and challenges. Energy Environ. Sci. 2018, 11 (5), 1177-1196.

(18) Brogioli, D.; La Mantia, F.; Yip, N. Y. Thermodynamic analysis and energy efficiency of thermal desalination processes. Desalination 2018, 428, 29-39.

(19) Brogioli, D.; La Mantia, F.; Yip, N. Y. Energy efficiency analysis of distillation for thermally regenerative salinity gradient power technologies. Renewable Energy 2019, 133, 1034-1045.

(20) Boo, C.; Elimelech, M. Thermal Desalination Membranes Carbon nanotubes keep up the heat. Nat. Nanotechnol. 2017, 12 (6), 501-503.

(21) Shahzad, M. W.; Burhan, M.; Ng, K. C. A standard primary energy approach for comparing desalination processes. npj Clean Water 2019, 2 (1), 1.

(22) Burkin, A. R. Handbook of Solvent Extraction; Lo, T. C., Baird, M. H. I., Hanson, C., Eds.; Krieger Publishing Co., 1984; pp 584.

(23) Vivona, L. Handbook of Solvent Extraction; Lo, T. C., Baird, M. H. I., Eds.; Krieger Publishing Co., 1983; Vol. 90, pp 261.

(24) Letellier, M.; Budzinski, H. Microwave assisted extraction of organic compounds. Analusis 1999, 27 (3), 259-271.

(25) Natusch, D. F. S.; Tomkins, B. A. Isolation of Polycyclic Organic-Compounds by Solvent-Extraction with Dimethyl-Sulfoxide. Anal. Chem. 1978, 50 (11), 1429-1434.

(26) Chemat, F.; Vian, M. A.; Cravotto, G. Green Extraction of Natural Products: Concept and Principles. Int. J. Mol. Sci. 2012, 13 (7), 8615-8627.

(27) Xie, F.; Zhang, T. A.; Dreisinger, D.; Doyle, F. A critical review on solvent extraction of rare earths from aqueous solutions. Miner. Eng. 2014, 56, 10-28.

(28) Davidson, R. R.; Smith, W. H.; Hood, D. W. Structure and Amine-Water Solubility in Desalination by Solvent Extraction. J. Chem. Eng. Data 1960, 5 (4), 420-423.

(29) Davison, R. R.; Harris, W. B.; Smith, W. H. A solvent extraction desalination pilot plant. Desalination 1967, 3 (1), 17-26.

(30) Bajpayee, A.; Luo, T. F.; Muto, A.; Chen, G. Very low temperature membrane-free desalination by directional solvent extraction. Energy Environ. Sci. 2011, 4 (5), 1672-1675.

(31) McMurry, J. Organic chemistry, 9th ed.; Cengage Learning: Boston, 2016; p xxx, 1054, 59.

(32) Weigand, C. L. From email to earthquakes: On teaching and learning with technology in the California State University; California State University Press: Long Beach, CA, 2003; p xiii, 352 p.

(33) Davison, R. R.; Hood, D. W. Thermodynamic Cycles for Recovery of Water by Solvent Extraction. Ind. Eng. Chem. Process Des. Dev. 1964, 3 (4), 399-404.
(34) Zemaitis, J. F. Handbook of aqueous electrolyte thermodynamics: Theory \& application; Design Institute for Physical Property Data sponsored by the American Institute of Chemical Engineers: New York, 1986; p xxi, 852 p. 